\title{
Serum uric acid as marker of severity of pre-eclampsia
}

\author{
Shirish Toshniwal*, Aakriti R. Lamba
}

Department of Obstetrics and Gynecology, Civil Hospital, Ahmedabad, Gujrat, India

Received: 26 August 2017

Accepted: 25 September 2017

\section{*Correspondence:}

Dr. Shirish Toshniwal,

E-mail: aakritilambaji@gmail.com

Copyright: (c) the author(s), publisher and licensee Medip Academy. This is an open-access article distributed under the terms of the Creative Commons Attribution Non-Commercial License, which permits unrestricted non-commercial use, distribution, and reproduction in any medium, provided the original work is properly cited.

\begin{abstract}
Background: In pre-eclampsia, there is increased uteroplacental resistance and reduced foetal perfusion due to inadequate invasion of spiral arterioles by trophoblast cells. This causes impaired foetal growth and foetal hypoxia. To assess the usefulness of foetal Doppler in predicting adverse perinatal outcome in preeclampsia.

Methods: All the women with preeclampsia from 30 weeks onwards were enrolled in the study. The umblical artery (UA) Systolic-diastolic (S/D) ratio > 2 standard deviation (SD) or UA - Pulsatility Index (PI) and UA - Resistive Index (RI) > 2 SD were taken as abnormal. The middle cerebral artery (MCA) was visualised and cerebroumblical PI ratio calculated. MCA-RI <2SD was taken as abnormal.

Results: There were 107 women in the study. Major adverse outcomes 11. Umbilical artery - S/D ratio >2SD (RR 4.46, 95\%, CI 1.40-14.17) and RI >2SD (RR 3.36, 95\%, CI 1.03-10.61) and MCA RI <2SD (RR 4.46, 95\% CI 1.414.17) had a high relative risk to predict adverse major perinatal outcome. 39 babies were admitted in neonatal nursery and no parameters could predict them. Though UA - PI > 2SD predicted acute foetal distress in labour (RR $2.33,95 \%$ CI 1.21-4.47), there was no association on multivariate regression analysis.

Conclusions: This study showed UA-S/D ratio and UA-RI $>2$ SD are significant predictors of perinatal deaths and immediate neonatal resuscitation in preeclampsia. Acute foetal distress in labour or neonatal nursery admission could not be predicted.
\end{abstract}

Keywords: Pre-eclampsia, Serum uric acid

\section{INTRODUCTION}

Pre-eclampsia is still one of the most important causes of maternal and foetal mortality. ${ }^{1}$ The aetiology of preeclampsia still remains unexplained. Though endothelial dysfunction is considered to play a central role in pathophysiology of it. $^{2}$ There was no screening test reliable enough to diagnose pre-eclampsia. Uric acid is one of the most sensitive indicators of disease severity in pregnancy induced hypertensive disorders and can be of great help in monitoring the cause of disease process. ${ }^{3}$ Several studies have demonstrated a correlation between elevated maternal serum uric acid and adverse maternal and foetal outcome. ${ }^{4}$ Uric acid is a product of purine degradation catalysed by the enzyme xanthine oxidase. In normal pregnant women serum uric acid concentration initially falls $25-30 \%$ due to elevation in renal clearance secondary to increased GFR or reduced proximal tubular reabsorption due to changes in its production rate. Later in pregnancy the serum uric acid levels increase due to foetal production, decreased uric acid clearance and decreased binding to albumin. ${ }^{5}$ Uric acid is filtered, reabsorbed and secreted by the kidney. The most commonly accepted explanation for hyperuricemia is increased reabsorption and decreased excretion of uric acid. $^{6}$

Uric acid is a potent mediator of inflammation. Uric acid stimulates monocytes to produce pro-inflammatory cytokines IL-1 $\beta$, IL-6, TNF- $\alpha$. Uric acid promotes endothelial dysfunction per se which could promote hypertension, vascular disease and renal disease. 
Therefore, the present study was designed to assess the association of uric acid levels in pre-eclampsia.

\section{METHODS}

A case control study was conducted in the Obstetrics and Gynecological Department of Civil Hospital Ahmedabad. A total of 50 pregnant women in third trimester of pregnancy were taken as study subjects. 50 historical control subjects were selected. Out of 50 case subjects 22 were diagnosed as PIH, 16 were labelled as mild preeclampsia and 12 as severe pre-eclampsia. Pregnant women with pre-existing hypertension, diabetes mellitus and renal disease were excluded from the study by the history, clinical examination and relevant laboratory investigations. After obtaining informed written consent from all the study subjects relevant data were documented in a predefined data sheet and blood samples were collected from study subjects for estimation of serum uric acid levels.

\section{RESULTS}

In Table 1, distribution and comparison of age was studied. Most of the subjects belonged to 21-30 years of age (cases $74 \%$, controls $88 \%$ ).

Table 1: Distribution and comparison of age.

\begin{tabular}{|lll|}
\hline Age (years) & Case $(n=50)$ & Controls $(n=50)$ \\
\hline$<20$ & $7(14 \%)$ & $4(8 \%)$ \\
\hline $21-30$ & $37(74 \%)$ & $44(88 \%)$ \\
\hline $31-40$ & $6(12 \%)$ & $2(4 \%)$ \\
\hline
\end{tabular}

Other parameters in terms of gravida, gestational age and antenatal health check-ups were taken into consideration and listed in Table no 2, 3 and 4.

Table 2: Distribution and comparison of gravida in study subjects.

\begin{tabular}{|lll|}
\hline Study subjects & Primigravida & Multigravida \\
\hline Cases $(\mathrm{n}=50)$ & $40(80 \%)$ & $10(20 \%)$ \\
\hline Controls $(\mathrm{n}=50)$ & $36(72 \%)$ & $14(28 \%)$ \\
\hline
\end{tabular}

Table 3: Distribution and comparison of gestational age in study subjects.

\begin{tabular}{|ll|}
\hline Study subjects & Gestational age (Mean) \\
\hline Cases $(n=50)$ & $32-34$ weeks \\
\hline Controls $(n=50)$ & $30-34$ weeks \\
\hline
\end{tabular}

Table 4: Status of antenatal check-up in study subjects.

\begin{tabular}{|lll|}
\hline Antenatal check up & Cases $(\mathbf{n = 5 0})$ & Controls $(\mathbf{n}=50)$ \\
\hline Regular & $8(16 \%)$ & $18(36 \%)$ \\
\hline Irregular & $26(52 \%)$ & $20(40 \%)$ \\
\hline None & $16(32 \%)$ & $12(24 \%)$ \\
\hline
\end{tabular}

Table 5 shows comparison of serum uric acid concentration between cases and controls. Mean with standard deviations of cases (Mean \pm SD $=7.52 \pm 1.90)$ were compared with that of controls (Mean $\pm \mathrm{SD}=$ $4.55 \pm 1.63)$. The levels were statistically significant $(p$ value $=0.0001)$.

Table 5: Comparison of serum uric acid concentrations between cases and controls.

\begin{tabular}{|llll|}
\hline Parameter & Cases & Number & Mean \\
\hline \multirow{2}{*}{$\begin{array}{l}\text { Serum uric } \\
\text { acid }\end{array}$} & PIH & 22 & 6.89 \\
\cline { 2 - 4 }$(\mathrm{mg} / \mathrm{dl})$ & Mild pre-eclampsia & 16 & 7.60 \\
\cline { 2 - 4 } & Severe pre-eclampsia & 12 & 8.33 \\
\cline { 2 - 4 } & Total & 50 & 7.52 \\
\hline
\end{tabular}

\section{DISCUSSION}

The study was aimed at finding the association between serum uric acid and pre-eclampsia. In the present study no significant difference was observed between two groups regarding maternal age and gestational age.

The study revealed increased incidence of pre-eclampsia in primigravidas. A similar conclusion was drawn by Odegard et al where they showed nulliparity as a risk factor of pre-eclampsia. ${ }^{7}$

Most number of cases and controls were irregular in antenatal checkups.

Hyperuricemia is common in pregnancies complicated with pre-eclampsia. In normal pregnancy serum uric acid level slowly decreases until about 16 weeks of gestation, secondary to plasma volume expansion, increased renal clearance and uricosuric effect of estrogen.

For the most of second trimester uric acid levels remain stable, then it increases in $3^{\text {rd }}$ trimester because of increased production.

In the present study, the observation showed significant difference between the two forms of pre-eclampsia i.e., mild and severe and PIH suggesting uric acid to be a good marker of severity of disease. In pre-eclampsia, uric acid levels have been known to increase and to correlate with maternal and fetal morbidity but always have been assumed to be a reflection of a disease rather than a cause. However, several other studies showed that serum uric acid is poor predictor of pre-eclampsia. ${ }^{8}$

\section{CONCLUSION}

Serum uric acid can be a useful indicator of maternal and foetal complication in hypertensive pregnancies.

Funding: No funding sources

Conflict of interest: None declared

Ethical approval: The study was approved by the Institutional Ethics Committee 


\section{REFERENCES}

1. Sibai BM, Gordon T, Thom E. Risk factors for preeclampsia in healthy nulliparous women. Am J Obstet Gynnecol. 1995; 172;642-8.

2. Dekker GA, Sibai BM. Etiology and pathogenesis of pre-eclampsia. Am J Obstet Gynecol. 1998;179(5);1359-75.

3. Soomro N, Shazia. Serum uric acid as a predictor model for pre-eclampsia. Pak J Surg. 2010;26(3);246-51.

4. Lancet M, Fisher IL. The value of blood uric acid in toxaemia of pregnancy. J Obstet Gynecol. 1956;63;116-9.

5. Powers RW, Bodnar LM, Ness RB. Uric acid concentration in early pregnancy among pre- eclamptic women with gestational hyperuricemia of pregnancy. Am J Obstet Gynecol. 2006;194;160.

6. Many A, Hubel CA, Roberts JM. Hyperuricemia and xanthine oxidase in pre-eclampsia. Am J Obstet Gynecol. 1996;174;228-91.

7. Odegard RA, Vatten LJ, Nilsen ST, Salvasen KA, Austgulen R. Risk factors and clinical manifestations of pre-eclampsia. $\mathrm{Br} \mathrm{J}$ Obstet Gynecol. 2002;107;1410-6.

8. Dekker GA, Sibai BM. Early prediction of preeclampsia. AM J Obstet Gynecol. 1998;165;160-72.

Cite this article as: Toshniwal S, Lamba AR. Serum uric acid as marker of severity of pre-eclampsia. Int $\mathbf{J}$ Reprod Contracept Obstet Gynecol 2017;6:4915-7. 